ORIGINAL ARTICLE

\title{
Effect of farming environment on sensitisation to allergens continues after childhood
}

\author{
H O Koskela, K K Happonen, S T Remes, J Pekkanen
}

Occup Environ Med 2005;62:607-611. doi: 10.1136/oem.2004.014852

See end of article for authors' affiliations

.....................

Correspondence to: Dr H O Koskela, Department of Respiratory Medicine, Kuopio University Hospital, PL 1777, 70210 Kuopio, Finland; heikki.koskela@ kuh.fi

Accepted 25 February 2005
Aims: The farming environment in childhood has been reported to decrease the risk of sensitisation to allergens. The purpose of the present study was to explore whether later exposure to a farming environment also could affect this sensitisation.

Methods: A population based sample of 202 women who did not live on a farm and 231 who did. The subjects filled in a questionnaire and underwent skin prick tests for several common and farming related allergens.

Results: The prevalence of sensitisation to any of the allergens was similar in the two groups (37.1 v 34.6\% $(p=N S)$. However, compared with women who did not live on a farm, the women who lived on a dairy farm showed a low prevalence of sensitisation to pollens $(4.4 v 17.3 \%, p=0.01)$ and cats $(3.5 v 10.4 \%$, $p=0.047)$. The risk of sensitisation to pollens and pets was lowest among women with both a childhood and adulthood farming environment and was dose dependently associated with current contact with farm animals. However, this contact increased the risk of sensitisation to bovine dander.

Conclusion: The farming environment may reduce sensitisation to common allergens also after early childhood. However, it may also increase sensitisation to farm allergens.
1 t has been consistently shown that childhood exposure to a farming environment is associated with a low prevalence of sensitisation to common allergens. ${ }^{1-8}$ This protection may last up to adulthood. ${ }^{4-10}$ Indeed, the European Farmers' Study showed that the prevalence of wheezing, shortness of breath, asthma, and nasal allergies was significantly lower among farmers in the age group 20-44 years than among the general population. ${ }^{11}$ Although the mechanisms of this postulated "protective farm effect" are not fully understood, it has been suggested that exposure to the high ambient endotoxin concentrations typical in a farming environment might enhance the process of polarisation of the immune system from a T-helper 2 (Th2) to a Th1 (non-allergic) response pattern, ${ }^{12-14}$ a process called immune deviation. ${ }^{15}$ This process is established by 5 years of age, ${ }^{16}$ which would fit findings suggesting that a very early exposure to a farming environment is essential with respect to the protective farm effect. ${ }^{6}{ }^{10}$ However, some authors argue that the available epidemiological evidence may not provide support for this mechanism of early immune deviation and have suggested that the environmental influences on atopic disease are likely to occur throughout the life. ${ }^{17} 18$ The present study was planned to investigate whether the effect of the farming environment on sensitisation to common allergens is restricted to early childhood or exists throughout life. In Finnish farms, women traditionally take care of cattle and previous studies have suggested that contact with animals is essential for the protective farm effect. ${ }^{5}{ }^{19}$ Therefore, only women were invited to the present study.

\section{METHODS}

\section{Study population}

This study was carried out in the 17 municipalities of the former Kuopio County. The study area consisted of mostly rural areas with few small towns. The present study is connected with a study about the effect of the farming environment on children. ${ }^{20}$ Firstly, 462 children aged 6-13 years whose father's occupation was a farmer and an equal number of randomly selected non-farmers' children were drawn from the Central Population Registry. The population of the present study consists of the mothers of these children. However, due to practical reasons, the examination of the mothers was started only after the children of the first two municipalities had already been studied. Therefore, only the 676 of the 924 mothers were invited. They were asked to visit a nearby school where the skin prick tests were performed and the questionnaires were given. Informed written consent was obtained from every participant and the study was approved by the Ethical Committee for Human Research of Kuopio University Hospital, Finland.

\section{Questionnaire and definition of certain variables}

The questionnaire and symptoms of the present study population have been reported before. ${ }^{21}$ If the subject answered positively to the questions "Does your family practice farming?" and "Does your family live on the farm?" she was classified to the group "living on a farm". The subjects were also asked to define the type of farming and the farms were then divided to groups "dairy farming", "other animal husbandry" (including beef cattle farming, poultry farming, and swine farming), and "crop farming". The subjects were also asked if they worked on the farm full time, part time, or not at all. Those who participated to animal husbandry were asked how many years they had worked with farm animals and how often they had visited the animal shed during the last 12 months. "Childhood farming environment" was defined as having lived the first year of life on a farm. "Parental atopy" was defined as a presence of asthma, hay fever, or atopic dermatitis in either of the parents. "Non-smoker" was a person who had not smoked for at least one year. "Ex-smoker" was a person who had smoked at least one cigarette daily for at least one year ever in lifetime but who had stopped smoking at least one month ago. "Current smoker" was a person who currently smoked at least one cigarette daily. 
Table 1 Basic characteristics of the subjects

\begin{tabular}{|c|c|c|c|}
\hline & $\begin{array}{l}\text { Not living on } \\
\text { a farm, } n=202\end{array}$ & $\begin{array}{l}\text { Living on a } \\
\text { farm, } n=231\end{array}$ & p Value \\
\hline Mean (SD) age (years) & $39.2(5.7)$ & $41.5(5.7)$ & NS \\
\hline $\begin{array}{l}\text { Mean (SD) body mass } \\
\text { index }\left(\mathrm{kg} / \mathrm{m}^{2}\right)\end{array}$ & $25.2(4.1)$ & $25.2(3.9)$ & NS \\
\hline Ex smokers (\%) & 23 & 12 & 0.005 \\
\hline Current smokers (\%) & 10 & 5 & 0.047 \\
\hline $\begin{array}{l}\text { Mean (SD) length of } \\
\text { education (years) }\end{array}$ & $13.0(2.7)$ & $13.2(2.7)$ & NS \\
\hline $\begin{array}{l}\text { Having cats or dogs } \\
\text { indoors currently (\%) }\end{array}$ & 34 & 55 & $<0.0001$ \\
\hline Parental atopy (\%) & 40 & 41 & NS \\
\hline $\begin{array}{l}\text { Mean (SD) number of } \\
\text { older siblings }\end{array}$ & $1.8(1.7)$ & $1.9(2.0)$ & NS* \\
\hline $\begin{array}{l}\text { Childhood farming } \\
\text { environment (\%) }\end{array}$ & 49 & 70 & $<0.0001$ \\
\hline $\begin{array}{l}\text { Having had pets during } \\
\text { childhood (\%) }\end{array}$ & 73 & 78 & NS \\
\hline $\begin{array}{l}\text { Passive smoking during } \\
\text { childhood (\%) }\end{array}$ & 69 & 53 & 0.001 \\
\hline $\begin{array}{l}\text { Allergic dermatitis } \\
\text { during childhood (\%) }\end{array}$ & 23 & 22 & NS \\
\hline $\begin{array}{l}\text { Childhood day care } \\
\text { attendance (\%) }\end{array}$ & 2.0 & 1.7 & NS \\
\hline
\end{tabular}

*Due to the skewed distribution, Mann-Whitney $U$ test was used. The continuous variables are expressed as means and standard deviations in parenthesis, and compared by Student's $t$ test between the groups. The categorical variables are expressed as percentages, and the comparisons between the groups were carried out using Fisher's exact test.

\section{Skin prick tests}

The testing was carried out in the 2001, during winter to avoid the influence of pollen season, by a single fieldworker, according to the International Study of Asthma and Allergies in Childhood protocol. ${ }^{22}$

A panel of 10 allergens was used (Soluprick SQ, ALKAbelló, Copenhagen, Denmark). Seven of the allergens were standardised (birch, timothy grass and mugwort pollens, cat, dog, horse dander, and house dust mite (Dermatophagoides pteronyssinus)), and three were not (bovine dander, cockroach, and storage mite (Lepidoglyphus destructor)). The concentration of the standardised extracts was 10 histamine equivalent prick; the concentrations of the non-standardised extracts were 100 biological units (storage mite) and 1:100 weight/ volume (bovine dander and cockroach). Histamine dihydrochloride $(10 \mathrm{mg} / \mathrm{ml})$ and glycerol $(50 \%)$ were used as positive and negative controls, respectively. The same batch of each solution was used throughout the study. For a test to be included in the final analyses, the reaction to the positive control had to be at least $3 \mathrm{~mm}$, and the reaction to the negative control had to be $1 \mathrm{~mm}$ or less. A reaction of $3 \mathrm{~mm}$ or greater to the allergens was considered positive.

\section{Statistical analysis}

Prevalence of the various characteristics and the sensitisation to common allergens between the groups were compared by Fisher's exact test (two groups) and $\chi^{2}$ test (more than two groups). Student's $t$ test was also used in between-groups comparisons. The confounders for the logistic regression models were chosen in the following way: A potential confounder was chosen if its prevalence varied significantly between the study groups (table 1) and if it could potentially affect the main outcome-that is, sensitisation to allergens. The following potential confounders were found: childhood farming environment, passive smoking during childhood, currently having cat or dog mostly indoors, and never, ex, and current smoking. The confounder was included in the final models if adjusting for the potential confounder changed the odds ratio (OR) of a particular farming characteristic by $10 \%$ or more. In addition, we performed the logistic regression analysis including all the above mentioned potential confounders plus age in the models. It changed the results very little (data not shown). The interaction effect of childhood farming environment and current farming environment on sensitisation to allergens was tested by creating a new variable ("the interaction variable") by multiplying the childhood farming exposure $(0$ or 1) with adulthood farming exposure (0 or 1). All analyses were carried out using SPSS for Windows 10.0 (SPSS Inc, Chicago, IL, USA).

\section{RESULTS \\ Population}

Of the 676 women invited to the study, 511 (75.6\%) participated in skin prick testing and a total of $466(68.9 \%)$ women returned the questionnaire. Twenty eight subjects with a positive reaction to the negative control and four subjects with a negative reaction to histamine were excluded from the analyses. Complete data including acceptable skin prick test results and questionnaire were obtained from 433 women (64.1\% of invited). Of the 165 women who did not participate in skin prick testing, there were more women who did not live on a farm $(58.8 \%)$ than those who did $(41.2 \%)$.

Table 2 Prevalences of sensitisation to specific allergens, expressed in percentages

\begin{tabular}{|c|c|c|c|c|c|c|c|}
\hline & $\begin{array}{l}\text { Not living on a } \\
\text { farm, } n=202\end{array}$ & $\begin{array}{l}\text { Living on a farm, } \\
n=231 \quad(50,65, \\
116)^{*}\end{array}$ & p Valuet & $\begin{array}{l}\text { Living on a } \\
\text { dairy farm, } \\
n=113 \\
(12,19,82)\end{array}$ & $\begin{array}{l}\text { Living on a farm } \\
\text { with other types of } \\
\text { animal husbandry, } \\
n=38(8,11,19)\end{array}$ & $\begin{array}{l}\text { Living on a crop } \\
\text { farm, } n=80(30 \text {, } \\
35,15)\end{array}$ & p Value \\
\hline Timothy grass & 9.4 & 5.6 & 0.14 & 2.7 & 5.3 & 10.0 & 0.11 \\
\hline Birch & 10.4 & 5.2 & 0.047 & 2.7 & 5.3 & 8.8 & 0.08 \\
\hline Mugwort & 6.9 & 5.6 & 0.69 & 1.8 & 10.5 & 8.8 & 0.11 \\
\hline Any of the pollens & 17.3 & 10.4 & 0.049 & 4.4 & 15.8 & 16.3 & 0.01 \\
\hline Dog & 13.9 & 10.8 & 0.38 & 6.2 & 15.8 & 15.0 & 0.15 \\
\hline Cat & 10.4 & 6.5 & 0.16 & 3.5 & 2.6 & 12.5 & 0.047 \\
\hline Dog or cat & 15.8 & 12.1 & 0.27 & 7.1 & 15.8 & 17.5 & 0.11 \\
\hline House dust mite & 7.9 & 8.2 & 1.0 & 8.0 & 7.9 & 8.8 & 1.0 \\
\hline Cockroach & 8.9 & 11.3 & 0.43 & 12.4 & 13.2 & 8.8 & 0.68 \\
\hline Storage mite & 10.9 & 8.7 & 0.52 & 11.5 & 7.9 & 5.0 & 0.41 \\
\hline Horse & 2.5 & 4.8 & 0.31 & 4.4 & 0.0 & 7.5 & 0.13 \\
\hline Bovine dander & 0.0 & 7.8 & $<0.0001$ & 12.4 & 2.6 & 3.8 & $<0.0001$ \\
\hline Any of the allergens & 37.1 & 34.6 & 0.62 & 31.9 & 36.8 & 37.5 & 0.79 \\
\hline
\end{tabular}

*Within each category, the first number in parentheses indicates the number of subjects who did not actively participate in farm work, the second number indicates half time farm workers, and the third number indicates full time farm workers.

†Fisher's exact test between the groups "not living on a farm" and "living on a farm".

$\ddagger \chi^{2}$ test between the groups "not living on a farm", "dairy farm", "other animal husbandry", and "crop farm". 
Table 3 Risk of sensitisation to various allergens with respect to childhood and current farming environment

\begin{tabular}{lrlll}
\hline $\begin{array}{l}\text { Living on a farm in } \\
\text { childhood/adulthood }\end{array}$ & $\mathbf{n}$ & $\begin{array}{l}\text { OR }(95 \% \mathrm{Cl}) \text { of } \\
\text { sensitisation to any of } \\
\text { the pollens* }\end{array}$ & $\begin{array}{l}\text { OR }(95 \% \mathrm{Cl}) \text { of } \\
\text { sensitisation to dog or } \\
\text { cat }^{*}\end{array}$ & $\begin{array}{l}\text { Prevalence of } \\
\text { sensitisation to bovine } \\
\text { dander }(\%) \dagger\end{array}$ \\
\hline No/no & 103 & 1 & 1 & 0 \\
No/yes & 70 & $0.93(0.44-2.0)$ & $0.74(0.33-1.7)$ & 5.7 \\
Yes/no & 99 & $0.55(0.26-1.2)$ & $0.49(0.22-1.1)$ & 0 \\
Yes/yes & 160 & $0.18(0.08-0.42)$ & $0.36(0.17-0.74)$ & 8.8 \\
\hline & & &
\end{tabular}

Of the 433 women with acceptable skin test and questionnaire, there were 202 who did not live on a farm and 231 who did (table 1). The distribution of various types of farms is expressed in table 2 . Typically for eastern Finland, small dairy farms predominated, containing a mean of 25 cows. The women who lived on a farm were asked whether they actively participated in the farm work and the results of this question are expressed in table 2. The subjects were also asked whether they had quitted farming or had decided not to become a farmer due to allergic symptoms. Only six subjects answered yes to this question-three who did not live on a farm and three who did.

\section{Sensitisation to allergens}

The overall prevalence of sensitisation to any allergens did not differ between the women who did not live on a farm and the women who lived on various types of farms (table 2). However, the prevalence of sensitisation to pollens and pets (and cat especially) was lowest among women who lived on a dairy farm (table 2). On the contrary, the prevalence of sensitisation to bovine dander was most common among these women. Table 3 shows that the lowest risk of sensitisation to pollens and pets was among women with both a childhood and adulthood farming environment. However, these women also showed the highest prevalence of sensitisation to bovine dander. The "interaction variable" tended to associate with sensitisation to pollens $(p=0.067)$ but not with sensitisation to pets $(p=0.91)$. Table 4 shows that the intensity and duration of animal husbandry was dose dependently associated with a decreased risk of sensitisation to pollens. Such an association could also be shown in sensitisation to pets, though less clearly. Again, an opposite pattern could be observed in sensitisation to bovine dander. The duration and intensity of animal husbandry correlated significantly ( $\mathrm{p}<0.001, \chi^{2}$ test) demonstrating that those with the most frequent visits to the animal shed usually had worked for the longest time with farm animals.

\section{DISCUSSION}

This study showed that the overall prevalence of sensitisation to allergens does not differ between women who live on a farm and women who do not. However, there were clear differences in the targeting of sensitisation. The women who lived on dairy farms showed decreased risks of sensitisation to pollens and pets and an increased risk of sensitisation to bovine dander, in a dose dependent manner with respect to current contacts with farm animals. When the effects of childhood and adulthood farming environment were analysed separately, those with both childhood and adulthood farming exposure showed the lowest risks of sensitisation to pollens and pets. These findings suggest that the farming environment affects sensitisation to allergens throughout life, not just during childhood.

Our findings indicate that the immune deviation hypothesis $^{15}$ may not fully explain the low prevalence of sensitisation to common allergens among adult farmers ${ }^{911} 2324$ as this deviation is thought to be established by 5 years of age. ${ }^{16}$ Therefore, other mechanisms should be considered. Recently the term "immune modulation" has been introduced whereby both Th1 and Th2 responses are enhanced or suppressed in concert, throughout life. ${ }^{17}{ }^{18}$ This immune modulation might involve the action of the so called $\mathrm{T}$ regulatory cells. ${ }^{25}$ These cells form a heterogeneous family. A subset called adaptive $\mathrm{T}$ regulatory cells acquires suppressive activity in the periphery under certain conditions of antigenic stimulation. It is tempting to speculate that there is a farm related factor which could stimulate the adaptive $\mathrm{T}$ regulatory cells, which, in turn, could suppress IgE mediated responses

Table 4 Risk of sensitisation to various allergens with respect to contacts with farm animals. Because of the small number of subjects sensitised to bovine dander adjusted ORs could not be calculated

\begin{tabular}{|c|c|c|c|c|}
\hline & $\mathbf{n}$ & $\begin{array}{l}\text { OR }(95 \% \mathrm{Cl}) \text { of } \\
\text { sensitisation to } \\
\text { any of the pollens }\end{array}$ & $\begin{array}{l}\text { OR }(95 \% \mathrm{Cl}) \text { of } \\
\text { sensitisation to } \\
\text { dog or cat }\end{array}$ & $\begin{array}{l}\text { Prevalence of } \\
\text { sensitisation to bovine } \\
\text { dander }(\%)\end{array}$ \\
\hline \multicolumn{5}{|l|}{$\begin{array}{l}\text { Visits in animal shed during } \\
\text { the last } 12 \text { months }\end{array}$} \\
\hline No visits & 179 & 1 & 1 & 1.1 \\
\hline Less than once a week & 99 & $1.3(0.66-2.5)$ & $0.93(0.46-1.9)$ & 1.0 \\
\hline Once a week to once a day & 66 & $0.52(0.20-1.4)$ & $1.5(0.72-3.1)$ & 9.1 \\
\hline More than once daily & 88 & $0.41(0.15-1.1)^{*}$ & $0.28(0.09-0.86)^{*}$ & 10.2 \\
\hline \multicolumn{5}{|l|}{$\begin{array}{l}\text { Duration of work with farm } \\
\text { animals } \dagger\end{array}$} \\
\hline Not at all & 203 & 1 & 1 & 2.0 \\
\hline$<5$ years & 42 & $0.71(0.27-1.9)$ & $1.2(0.51-3.0)$ & 2.4 \\
\hline $5-15$ years & 58 & $0.30(0.10-0.90)$ & $0.48(0.18-1.3)$ & 1.7 \\
\hline$>15$ years & 94 & $0.21(0.07-0.62)^{*}$ & $0.67(0.30-1.5)^{*}$ & 11.7 \\
\hline
\end{tabular}

*Adjusted for smoking history and childhood farming environment.

†Thirty six subjects could not define the duration of work with animals. 
to common allergens throughout the life. The dose dependent association between the decreased risk of sensitisation to pollens and pets and the current contacts with dairy cattle suggests that this factor is somehow associated with farm animals. This finding is in close agreement with studies on children. $^{519}$ However, direct exposure data, like dust and endotoxin levels, ${ }^{26}$ have not been measured in the present study, which can be considered as a weakness of the study.

Previous studies comparing the sensitisation to common allergens between adult farmers and a control group corroborate our findings. Rautalahti et $a^{23}$ showed that dairy farmers in eastern Finland are less sensitised to cats, dogs, and mugwort than teachers. Filipiak et $\mathrm{al}^{24}$ found that farmers in southern Germany have lower risk for sensitisation against pollens and mites than non-farmers. In a recent study from Norway atopy (defined as a presence of IgE antibodies against common allergens) tended to be less prevalent among livestock farmers compared with crop farmers. ${ }^{27}$ In addition, prevalence of atopy was inversely associated with the duration of farm work. Unfortunately, IgE antibodies against bovine dander were not measured in that study.

What is the clinical importance of the present findings? Living on a farm was associated with decreased risks of sensitisation to pollens and pets. Sensitisation to these particular allergens is constantly associated with allergic rhinitis and asthma in the Nordic countries. ${ }^{28-32}$ We have previously reported considerably decreased risks of pet and pollen induced upper airway symptoms in the present farmer population. ${ }^{21}$ Therefore, a lifelong exposure to a farming environment might decrease the risk of allergic diseases by decreasing the risk of sensitisation to those allergens, which are most often associated with these diseases. However, the sensitisation to bovine dander was most common among women with the longest and most intensive exposure to cattle, suggesting that the heavy bovine allergen burden had outweighed the postulated protective farm effect. As a result, the overall prevalence of sensitisation to allergens did not differ between the women who lived on a farm and those who did not live. The sensitisation to bovine dander was also clinically important since our previous study showed that $28 \%$ of the present farmer population suffered from farm work related upper airway symptoms which were strongly associated with a positive skin test result to bovine dander. ${ }^{21}$ Thus, the present study does not suggest that farming would attenuate the overall prevalence of sensitisation to clinically important allergens. Furthermore, our findings suggest that when examining the effects of the farming environment on sensitisation to allergens, omitting the relevant farm related allergens from the test panel can lead to underestimation of skin test positivity.

One weakness of the present study is the somewhat lower participation rate among women who did not live on a farm. This may have lead to an overestimation of the prevalence of skin test positivity among them, as subjects with allergic symptoms may have been more keen to participate in allergy testing. However, this bias has less effect on the observed associations between the intensity of animal husbandry and the risks of sensitisation to various allergens. The present results are also potentially affected by the "healthy worker effect". ${ }^{33}$ However, in the present study all subjects were asked whether they had quitted farming or had decided not to become a farmer due to allergic symptoms. Only six subjects answered yes to this question-three who did not live on farm and three who did. A Swedish follow up study also speaks against significant health based selection among farmers. ${ }^{34}$

In conclusion, the present study suggests that the farming environment affects sensitisation to allergens throughout life and not just during early childhood. The net effect of the

\section{Main messages}

- The effect of the farming environment on sensitisation to allergens is not restricted to early childhood.

- An adulthood farming environment may decrease the risk of sensitisation to pollens and pets.

- Bovine husbandry seems to increase the risk of sensitisation to bovine dander.

\section{Policy implications}

- The mechanisms of the effects of an adulthood farming environment on sensitisation to allergens should be studied further.

- Sensitisation to bovine dander causes work related allergic symptoms. Thus, interventions to prevent this sensitisation should be considered in bovine farmers.

farming environment may not be necessarily protective as the decreased risk of sensitisation to common allergens like pets and pollens was accompanied by the increased risk of sensitisation to bovine dander.

\section{Authors' affiliations}

H O Koskela, Department of Respiratory Medicine, Kuopio University Hospital, Kuopio, Finland

K K Happonen, J Pekkanen, Unit of Environmental Epidemiology, National Public Health Institute, Kuopio, Finland

S T Remes, Department of Paediatrics, Kuopio University Hospital, Kuopio, Finland and Unit of Environmental Epidemiology, National Public Health Institute, Kuopio, Finland

Competing interest statement: none of the authors has any competing interest with respect to the manuscript.

Ethics approval: informed written consent was obtained from every participant and the study was approved by the Ethical Committee for Human Research of Kuopio University Hospital, Finland.

\section{REFERENCES}

1 Braun-Fahrlander C, Gassner M, Grize L, et al. Prevalence of hay fever and allergic sensitization in farmer's children and their peers living in the same rural community. SCARPOL team. Swiss Study on Childhood Allergy and Respiratory Symptoms with Respect to Air Pollution. Clin Exp Allergy 1999;29:28-34.

2 Ernst $P$, Cormier $Y$. Relative scarcity of asthma and atopy among rural adolescents raised on a farm. Am J Respir Crit Care Med 2000;161:1563-6.

3 Riedler J, Eder W, Oberfeld G, et al. Austrian children living on a farm have less hay fever, asthma and allergic sensitization. Clin Exp Allergy 2000;30:194-200.

4 Pekkanen J, Xu B, Jarvelin MR. Gestational age and occurrence of atopy at age 31 -a prospective birth cohort study in Finland. Clin Exp Allergy 2001;31:95-102

5 Downs SH, Marks GB, Mitakakis TZ, et al. Having lived on a farm and protection against allergic diseases in Australia. Clin Exp Allergy 2001;31:570-5.

6 Riedler J, Braun-Fahrlander C, Eder W, et al. Exposure to farming in early life and development of asthma and allergy: a cross-sectional survey. Lancet 2001;358:1129-33.

7 Leynaert B, Neukirch C, Jarvis D, et al. Does living on a farm during childhood protect against asthma, allergic rhinitis, and atopy in adulthood? Am J Respir Crit Care Med 2001; 164:1829-34.

8 Kilpelainen $\mathrm{M}$, Terho EO, Helenius $\mathrm{H}$, et al. Childhood farm environment and asthma and sensitization in young adulthood. Allergy 2002;57:1130-5.

9 Portengen L, Sigsgaard T, Omland O, et al. Low prevalence of atopy in young Danish farmers and farming students born and raised on a farm. Clin Exp Allergy 2002;32:247-53.

10 Radon K, Ehrenstein V, Praml G, et al. Childhood visits to animal buildings and atopic diseases in adulthood: an age-dependent relationship. Am J Ind Med 2004;46:349-56.

11 Radon K, Danuser B, Iversen M, et al. Respiratory symptoms in European animal farmers. Eur Respir J $2001 ; 17: 747-54$. 
12 von Mutius E, Braun-Fahrlander C, Schierl R, et al. Exposure to endotoxin or other bacterial components might protect against the development of atopy. Clin Exp Allergy 2000;30:1230-4.

13 Gereda JE, Leung DY, Thatayatikom A et al. Relation between house-dust endotoxin exposure, type 1 T-cell development, and allergen sensitisation in infants at high risk of asthma. Lancet 2000;355:1680-3.

14 Delayre-Orthez C, de Blay F, Frossard N, et al. Dose-dependent effects of endotoxins on allergen sensitization and challenge in the mouse. Clin Exp Allergy 2004;34:1789-95.

15 Holt PG, O'Keeffe P, Holt BJ, et al. T-cell "priming" against environmental allergens in human neonates: sequential deletion of food antigen reactivity during infancy with concomitant expansion of responses to ubiquitous inhalant allergens. Pediatr Allergy Immunol 1995;6:85-90.

16 Yabuhara A, Macaubas C, Prescott SL, et al. TH2-polarized immunological memory to inhalant allergens in atopics is established during infancy and early childhood. Clin Exp Allergy 1997;27:1261-9.

17 Julge K, Meriste S, Kemp A, et al. Atopic allergy and delayed type hypersensitivity in Estonian children. Clin Exp Allergy 2002;32:1420-3.

18 Kemp A, Bjorksten B. Immune deviation and the hygiene hypothesis: a review of the epidemiological evidence. Pediatr Allergy Immunol 2003;14:74-80.

19 Braun-Fahrlander C. The role of the farm environment and animal contact for the development of asthma and allergies. Clin Exp Allergy 2001:31:1799-803.

20 Remes ST, livanainen K, Koskela $\mathrm{H}$, et al. Which factors explain the lower prevalence of atopy amongst farmers' children? Clin Exp Allergy 2003;33:427-34.

21 Koskela HO, livanainen KK, Remes ST, et al. Pet- and pollen-induced upper airway symptoms in farmers and in nonfarmers. Eur Respir $J$ 2003;22:135-40.

22 Asher MI, Keil U, Anderson HR, et al. International Study of Asthma and Allergies in Childhood (ISAAC): rationale and methods. Eur Respir $J$ 1995:8:483-91.

23 Rautalahti M, Terho EO, Vohlonen I, et al. Atopic sensitization of dairy farmers to work-related and common allergens. Eur J Respir Dis Suppl 1987; 152:155-64.
24 Filipiak B, Heinrich J, Schafer T, et al. Farming, rural lifestyle and atopy in adults from southern Germany - results from the MONICA/KORA study Augsburg. Clin Exp Allergy 2001;31:1829-38.

25 Bluestone JA, Abbas AK. Natural versus adaptive regulatory T cells. Nat Rev Immunol 2003;3:253-7.

26 Radon K, Danuser B, Iversen M, et al. Air contaminants in different European farming environments. Ann Agric Environ Med 2002;9:41-8.

27 Eduard W, Douwes J, Omenaas E, et al. Do farming exposures cause or prevent asthma? Results from a study of adult Norwegian farmers. Thorax 2004;59:381-6.

28 Eriksson NE, Holmen A. Skin prick tests with standardized extracts of inhalant allergens in 7099 adult patients with asthma or rhinitis: cross-sensitizations and relationships to age, sex, month of birth and year of testing. J Investig Allergol Clin Immunol 1996;6:36-46.

29 Perzanowski MS, Ronmark E, Nold B, et al. Relevance of allergens from cats and dogs to asthma in the northernmost province of Sweden: schools as a major site of exposure. J Allergy Clin Immunol 1999; 103:1018-24

30 Plaschke PP, Janson C, Norrman E, et al. Onset and remission of allergic rhinitis and asthma and the relationship with atopic sensitization and smoking. Am J Respir Crit Care Med 2000;162:920-4.

31 Kihlstrom A, Lilja G, Pershagen G, et al. Exposure to birch pollen in infancy and development of atopic disease in childhood. J Allergy Clin Immunol 2002;110:78-84.

32 Ronmark E, Perzanowski M, Platts-Mills T, et al. Different sensitization profile for asthma, rhinitis, and eczema among 7-8-year-old children: report from the Obstructive Lung Disease in Northern Sweden studies. Pediatr Allergy Immunol 2003;14:91-9.

33 American Thoracic Society. Respiratory health hazards in agriculture. Am J Respir Crit Care Med 1998;158:S1-S76.

34 Thelin A, Hoglund S. Change of occupation and retirement among Swedish farmers and farm workers in relation to those in other occupations. A study of "elimination" from farming during the period 1970-1988. Soc Sci Med 1994;38:147-51. 